\title{
Pensar a educação do corpo na e para a escola: indícios no debate educacional brasileiro (1882-1927)
}

MARCUS AURELIO TABORDA DE OLIVEIRA Universidade Federal do Paraná

MEILY ASSBÚ LINHALES Universidade Federal de Minas Gerais

Parece-nos haver uma dimensão ainda pouco explorada nos estudos históricos relativos ao processo de escolarização primária ou elementar. Trata-se daquilo que chamamos de educação do corpo, uma das marcas mais tangíveis da difusão mundial da educação primária entre as décadas finais do século XIX e as primeiras décadas do século XX. Para sua realização, contribuíram discursos, dispositivos, práticas e saberes distintos em seu conteúdo e origem. Em trabalhos recentes, diferentes autores têm procurado lançar luzes sobre essa temática, ${ }^{1}$ e têm mostrado como os estudos sobre a história da educação do corpo se encontram entrelaçados a outras temáticas ou problemas de pesquisa, tais como: a educação dos sentidos e das sensibilidades, os rituais disciplinares, as prescrições científicas etc. - desdobramentos

1 Durante o IX Congreso Iberoamericano de Historia de la Educación Latinoamericana (2009), foram apresentados dois painéis integrados tratando da educação do corpo, que cobriam a Argentina, o Brasil, a Colômbia e o Uruguai. Na Argentina, Pablo Schagradosky e Angela Aisenstein têm se dedicado aos estudos sobre a história da educação do corpo. Para o caso uruguaio, temos os trabalhos de Raumar Rodriguez. Na Colômbia, Claudia Ximena Herrera Beltrán e William Moreno investigam diferentes expressões da educação do corpo. No Brasil, podemos citar Carmen Soares, Andrea Moreno, Alexandre Vaz, Tarcisio Vago, Kátia Danailoff, Silvana Goellner, entre outros. 
que fazem do corpo o lugar que abriga, rejeita, recebe, devolve, silencia ou anuncia a abundância de encontros com a natureza e com a cultura realizados pelos sujeitos.

Para dimensionar o olhar sobre tais peculiaridades, basta nos remetermos às preocupações com a definição de espaços e tempos apropriados ao projeto de escolarização, ao conjunto de formulações que refletiriam sobre a higiene, a saúde, o cansaço ou o divertimento dos escolares, à disposição dos chamados utensis materiais e equipamentos básicos, necessários para o fazer cotidiano nas escolas -, aos debates sobre os efeitos formativos da aplicação de castigos corporais ou sua impropriedade, à retórica da necessidade de disciplinar comportamentos infantis e ao desenvolvimento de diferentes rotinas e rituais. Por certo, todos esses elementos deram ênfase e visibilidade às dimensões de um projeto de formação moral, intelectual, e não só corporal. Nos propósitos deste trabalho, abordaremos prioritariamente o lento engendramento de algumas disciplinas escolares e outras práticas educativas realizadas na escola e em seu entorno, algumas com impressionante permanência. Tendo a educação do corpo como escopo básico, essas disciplinas e práticas delinearam um verdadeiro projeto de intervenção cultural.

Se esse projeto cultural comporta permanências, comporta também deslocamentos. Se ocorreram variações no trato pedagógico com os corpos infantis - tanto nos discursos, quanto nas práticas -, houve também a consolidação de uma ideia de civilidade que se fortalecia: a instituição de um ordenamento cultural capaz de afirmar que é possível e necessário educar as crianças e seus corpos. Temos aqui regras básicas que continuam a influenciar. Trata-se de algo que funda, baliza e expressa sentidos da história da educação na medida em que se repete e se modifica. São regras que se manifestarão nas proposições pedagógicas que, no Brasil, ganharam relevo no fim do século XIX e na primeira metade do século XX.

Assim, propomos, neste trabalho, considerar alguns momentos desse processo, articulando diferentes escalas geográficas. $O$ primeiro percorre os anos finais do século XIX e o início do século XX na província do Paraná, ao sul do Brasil, tardiamente emancipada - em 1853 - da província de São Paulo. A nova província pretendia modernizar-se, incorporando repertórios culturais produzidos em outros lugares, tidos como mais modernos. Muitos de seus intelectuais tentaram afirmar sua modernidade, estreitando as relações com outras províncias ou países com o propósito de firmar o Paraná como polo de modernização da sociedade brasileira. Por isso, nossa lente parte desse lugar particular para indagar outros esforços de discussão de um projeto nacional pela via da educação.

Justamente em Curitiba, capital do estado, teve lugar, em 1927, uma das primeiras tentativas nessa direção. Referimo-nos à realização da I Conferência Nacional de Educação (CNE), promovida pela Associação Brasileira de Educação (ABE), que pretendia discutir a educação como fator de progresso da nação. Nesse evento, a educação do corpo estaria presente em diversos pronunciamentos e teses de professores, médicos, dirigentes e reformadores. Se as discussões ocorriam em 
Curitiba, uma cidade distante de ser referência cultural à época, não devemos esquecer que essa primeira conferência surgia como uma pretensão de discutir a educação como problema nacional. Daí nos pareceu possível articular diferentes escalas de análise a partir de uma perspectiva temporal delimitada. Não pretendemos falar sobre $\circ$ Brasil, mas sobre possibilidades que vimos surgir nos embates pela organização da cultura nacional via discursos e práticas educativos.

Nessa trama de tempos e lugares, algumas referências já acumuladas sobre a história do currículo e das disciplinas escolares conjugaram nosso olhar sobre a história da educação do corpo.

\section{DISCIPLINAS ESCOLARES, CURRÍCULO E OUTROS ELEMENTOS DO PROCESSO DE ESCOLARIZAÇÃO}

Diferentes autores têm mostrado preocupações distintas com a configuração de um campo como a história do currículo. A principal preocupação dos estudiosos tem sido dimensionar em que medida a história do currículo e das disciplinas escolares pode contribuir para os debates contemporâneos sobre a definição curricular. Portanto, os pesquisadores têm se dedicado a pensar a educação e as práticas de escolarização naquilo que tende à mudança ou à estabilidade na média ou longa duração (Franklin, 1991; Sacristán, 2000; Goodson, 1995). Porém, outra preocupação especialmente interessante a um trabalho como este se refere à diferenciação entre história do currículo e história das disciplinas escolares, entendendo, no entanto, que ambas estão profundamente imbricadas, como lembra Souza (2005).

Por um lado, podemos afirmar que a história do currículo não pode prescindir da história das disciplinas escolares. Uma distinção possível para essas duas recentes possibilidades de estudo histórico da educação é aquela que compreende o currículo como um artefato social que inclui dimensões, tais como: a formação de professores e a ação docente, os tempos e espaços escolares, as ideias que informam o mundo da escolarização, as finalidades socioculturais que regem a escola, o aparato legislativo que a sustenta, os resultados do processo de escolarização - aquilo que Chervel (1990) denomina efeitos da escolarização-, chegando aos programas de ensino. $O$ currículo é essa construção social, ou tradição inventada, cortada por múltiplos determinantes e por processos não redutíveis à prescrição legal. Daí a riqueza de documentos aos quais o historiador do currículo pode recorrer para compreender o processo de construção, estabilização e mudança curricular.

Por outro lado, a história do currículo inclui a história das disciplinas, no sentido de que as disciplinas são parte de um construto maior que é o próprio currículo. Assim, seu estudo pode configurar-se a partir de recortes mais refinados, seja porque fazemos histórias de disciplinas específicas como canto orfeônico, desenho, educação física, história natural, higiene, trabalhos manuais etc., seja 
porque questões mais precisas ajudam a orientar as inquietações do historiador, tais como: conteúdos, finalidades, avaliação e exercícios, segundo a formulação de Chervel (1990).

Essas diferentes preocupações, oriundas de tradições historiográficas distintas, ajudam a entender a possibilidade de refinamento do diálogo entre a história do currículo e a história das disciplinas. Desse modo, a história do currículo, incluída aí a história das disciplinas escolares, é um campo privilegiado, ainda que em construção, para compreendermos as relações estabelecidas entre a escola, a educação do corpo e os movimentos mais amplos da sociedade e da cultura, que interfeririam em práticas e prescrições naquele âmbito. Nesse plano, ainda se torna importante ressaltar também os debates sobre a escolarização da sociedade. Pelos arranjos curriculares e pelas reinvenções permanentes das disciplinas, constitui-se uma estreita relação entre escola e sociedade, na qual a escola pode ser considerada uma dimensão significativa do longo processo de consolidação da modernidade. Logo, a instituição escolar apresenta-se como um objeto de investigação a suscitar variadas abordagens e construções teóricas e conceituais. ${ }^{2}$

Ao problematizar as relações que se estabelecem entre processos de escolarização e práticas de disciplinarização, Carvalho (1997) convida-nos ao debate sobre os múltiplos dispositivos que, na modernidade, constituem a forma (ou o modelo) escolar como estratégia socializadora que não se limita aos muros da escola. Vale notar que esse transbordamento da escolarização pelos espaços da cidade sempre foi estratégia recorrente nas ações relativas à educação do corpo. Nesse movimento, opera-se uma relação de trocas, de apropriações e negociação de sentidos e significados culturais. Nessa acepção, parece-nos necessário ressaltar que um investimento na educação do corpo representaria reconhecer seu lugar fundamental na realização da utopia do esclarecimento, uma vez que sobre e pelo corpo seriam elevadas as potencialidades morais e intelectuais dos indivíduos submetidos à escola. Olhando a história da escolarização por esse prisma, ela fecunda-se na história dos currículos e das disciplinas escolares, e a educação do corpo tem veio privilegiado para a compreensão da mudança ou da permanência no âmbito da cultura, no que se refere à educação dos sentidos e de novas sensibilidades.

2 Parece-nos relevante perceber a escolarização a partir da ideia thompsoniana de "motor da aceleração (e do distanciamento) cultural”, que, pela alfabetização, pelo conhecimento impresso e pelo esclarecimento organizado de cima para baixo, eclipsou outros processos educativos, especialmente os realizados pela transmissão oral, de geração para geração (Thompson, 1998, p. 18). Sobre a história do processo de escolarização, podemos contar com os estudos de Carvalho (1997, 1998 e 2003), Faria Filho (2000, 2002 e 2007); Vidal (2004 e 2005), Julia (2001 e 2002), Vincent (1994), Vincent, Lahire e Thin (2001), Pineau (1999). 


\section{ALGUNS INDÍCIOS DAS PRÁTICAS ESCOLARES}

Nos estudos relativos à história da educação, é sempre pertinente indagar em que medida os diferentes saberes expressos em múltiplas formas de circulação se tornaram práticas escolares. Não é fácil percorrer esse domínio, até mesmo pela natureza das fontes com as quais podemos contar. No caso deste trabalho, regulamentos de ensino, relatórios de professores, teses, pareceres, termos de visita de inspetores escolares foram mobilizados como possibilidade de compreender o corpo e sua educação como um dos pressupostos da escolarização em tempo e lugar definidos. Para identificar, nos documentos, indícios que permitissem sustentar tais premissas, partilhamos do pressuposto de que na "modernidade o corpo foi desvelado para a escolarização como 'lugar' privilegiado de acesso e conformação ao espírito dessa mesma modernidade, que tem no currículo escolar uma das suas mais caras invenções" (Taborda de Oliveira, 2006, p. 10).

Nos relatórios e na correspondência de professores, é possível sugerir alguns caminhos de pesquisa. Por exemplo, já na década de 1970, um relatório do professor José Cleto, da escola masculina de Paranaguá, no litoral paranaense, revela uma alusão aos divertimentos infantis como parte das práticas escolares. Infelizmente, as fontes disponíveis não permitem que façamos qualquer referência a essa dimensão da cultura. Todavia, a historiografia já registra que parte do que viria a se tornar "conteúdo" das disciplinas escolares de gymnastica e educação física teria nascido no âmbito da chamada "cultura popular". ${ }^{3}$ São jogos, brincadeiras, atividades acrobáticas, que faziam parte do patrimônio cultural produzido no emaranhado de sujeitos, ritos e modos simbólicos de variados tempos e lugares. No caso do Paraná, o máximo que as fontes permitem imaginar é um conjunto impreciso de folguedos infantis, que, para inúmeras propostas renovadoras, eram vistos como necessários ao bom desenvolvimento das crianças. Isso também pode ser dito do canto, que ocupava parte das atividades escolares. Ainda que algumas canções cívicas fizessem parte do acervo escolar, as chamadas cantigas tradicionais também ocupavam o mundo da escola. Para justificá-las, desenvolvia-se uma retórica higiênica sobre a necessidade da respiração e posturas adequadas, do uso controlado da voz, da harmonia do grupo etc. Em vários termos de visita dos anos 1880, observamos a referência aos exercícios de canto e de gymnastica, além dos trabalhos com agulhas e prendas domésticas.

3 A esse respeito, verificar os trabalhos de Vago (2002) e Soares (1998). Partilhamos a compreensão de que a noção de cultura popular é bastante imprecisa. Não obstante, ao usá-la, remetemos àquela produção cultural não codificada pelo escrutínio dos grupos ou classes dominantes. De qualquer modo, é preciso cuidado ao operar a noção tão sujeita a equívocos, conforme ensinam Carlo Ginzburg (1985) e Edward Thompson (1998). 
Vejamos um primeiro fragmento de práticas em relatório enviado ao diretor-geral da Instruç̧ão Pública, Raphael Teixeira Cardoso Pimentel, pelos professores Pedro Saturnino de Oliveira (1 ${ }^{\mathrm{a}}$ cadeira) e Joaquim Duarte de Camargo ( $2^{\mathrm{a}}$ cadeira), do município de Castro, em 30/11/1882:

Foram procedidos os exames dos alunos segundo a disposição do artigo 32 e 33 do Reg. da Instrução Publica de 16/07/1876. Os alunos foram submetidos às seguintes provas: leitura, escripta, arithmética, grammatica, doutrina christã e exercicios de gymnastica medica domestica. Tudo conforme as Instruções para os exames de classes, expedidos em 29 de novembro de 1859. A gymnastica foi lecionada na semana três dias, e em cada dia uma hora, conforme o art. $1 .^{\circ}$ das Instruções do Exmo. Sr. Dr. Presidente da Provincia.

Ainda em 1882, notemos um relatório vindo da cidade de Antonina. Para o coronel João Manuel Ribeiro Vianna, inspector parochial das escolas de Antonina, havia dificuldade de evitar "certos vicios e maus hábitos que adquiriram [os alunos]". Segundo o inspetor, isso poderia ter decorrido das constantes mudanças de professor e seus diferentes métodos. Não se aplicava nenhum método de ensino durante as aulas, porque seria impossível uniformizar os alunos em classes devido ao pouco adiantamento deles. Conforme o inspector:

É impossivel guardar a boa ordem e accomodar os alumnos com tão numerosas faltas de moveis. A sala é espaçosa e bem ventilada, bom quintal para o recreio. Possue um exemplar de "gymnastica" do professor Schreber tendo assim os meios precisos para o desenvolvimento physico dos meninos que necessariamente tirarão deles grande vantagem.

Destaque-se a ênfase no espaço para o recreio dos alunos e no manual de ginástica em contraposição às "numerosas faltas de móveis". Verificamos aqui traços de um quadro precário que, de forma um tanto estouvada, procurava modernizar-se. Conviviam, nem sempre de forma harmônica, a inovação dos registros discursivos e a rebeldia da realidade precária.

Em um termo de autoria não identificada, podemos observar que o autor do relatório ressalta o nome de dois alunos que "executam quase todos os exercícios ou figuras da gymnastica domestica, medica e hygienica de Schreber mandada executar". Por sua vez, as professoras Bernardina Rosa Rolim de Moura, da cidade de Castro, e Leocádia Maria da Rocha, da cidade de Antonina, falam-nos da influência da mulher na sociedade e do esforço da professora. De acordo com Bernardina Moura, "para incutir no espírito das alumnas [...] os princípios da moral para que se tornem dignas do nome de esposa e mãe. Procuro exercitar as alunas em trabalhos de agulha”. Leocádia da Rocha, por seu turno, anunciava os benefícios e o sucesso das avaliações realizadas em prendas domésticas. Nessa mesma direção, a professora Luiza Maria Huy, da cidade de Morretes, atestava 
que as alunas "forão avaliadas tanto nas matérias de ensino, como nos trabalhos de agulhas".

Um último fragmento vem da escola pública da cidade de Palmas. O inspetor paroquial Manoel Luís de Sousa, em 28/3/1883, relatou o andamento das aulas ministradas pelo prof. Ernesto Boese. Segundo Manoel de Sousa:

Tinham 34 alunos matriculados, sendo presentes no dia de visita 26 meninos e 4 meninas. Assisti aos 15 minutos de recreio que o professor usa de admittir aos alumnos depois das primeiras duas horas da sessão para divertirem-se com exercicios gymnasticos em baixo de sua vigilância. Achei útil e agradável este intervallo, pois vi, ao signal dado pelo mestre, voltarem os meninos mais alegres á continuação da sessão.

Não podemos atestar quais eram as práticas avaliadas, embora recorrer aos manuais possa ser uma alternativa fecunda, dada que a referência a esses documentos é absoluta. Ao observar que naqueles anos a gymnastica, os trabalhos com agulha e o canto eram avaliados, assim como as condições de higiene das escolas e das crianças e eram estimulados os jogos infantis, podemos concluir que estava em curso a definição das bases de algumas disciplinas escolares. Aqueles saberes e aquelas práticas ainda não configuravam rubricas autônomas. Mas certamente concorreram para estabelecer um lugar no currículo para algumas disciplinas que comporiam o programa da instrução pública primária nos anos seguintes no Paraná.

\section{A ORGANIZAÇÃO DE PRÁTICAS E SABERES: O CURRÍCULO DOS GRUPOS ESCOLARES}

Na primeira metade do século XX, o Brasil conheceu um intenso esforço de reformas da instrução pública em diferentes regiões, que, em muitos casos, estava sob o signo da chamada Escola Nova. Quando da proposta de renovação da instrução pública no estado do Paraná, na segunda década do século XX, o diretor-geral da Instruçção Pública, Francisco de Azevedo Macedo, defendia a seriação e a reforma do programa de ensino. Para esse segundo aspecto, pontificava:

Substituição de um programa anacbronico, antipedagógico, por outro próprio para o nosso tempo e no qual são postas em prática as mais bellas conquistas da Pedagogia; de um, de molde a produzir carecteres falhos, seres incompletos, fracos e passivos, por outro, capaz de fazer homens de ação, bem apparelhados de corpo e de espírito; de um, incompatível com os progressos da nova civilização, por outro que colocará a nossa escola primaria ao nível das mais adiantadas do mundo. (Paraná, 1914, p. 12)

Entre os 15 pontos prescritos no relatório para a $1^{\mathrm{a}}$ série, citado anteriormente, constavam cinco diretamente relacionados à educação do corpo: "Coló- 
quios variados e interessantes do professor e seus alumnos: para educar-lhes o sentido; desenho linear; noções sobre o som: som em geral, sons da música, sons da linguagem; exercícios de musica vocal: cânticos proprios para despertar o gosto artístico e os sentimentos superiores; trabalhos manuaes". Para a $2^{\text {a }}$ série, entre os 14 pontos, também observamos cinco com o mesmo tipo de preocupação: lições de cousas; exercícios caligráficos; desenho linear; cânticos escolares e trabalhos manuaes.

Para a $3^{\text {a }}$ série, observam-se sete pontos referentes ao corpo e à sua educação, no total de 14: exercícios de locução; continuação progressiva das lições de cousas; estudo do corpo humano; continuação progressiva do desenho natural; noções rudimentares de physica, chimica e história natural, com applicações úteis às artes e aos officios e especialmente à agricultura e à hygiene; cânticos escolares; trabalhos manuaes. Por fim, na $4^{a}$ série, contabilizamos sete matérias relacionadas ao tema. Entre 16 propostas: desenho do natural e da imaginação; recapitulação e ampliação das noções applicadas de physica, chimica e história natural; noções fundamentais e prática de agronomia; noções fundamentais e prática de hygiene; noções fundamentais de música: applicações em exercícios vocaes; trabalhos manuaes.

\section{O programa trazia ainda as seguintes observações:}

Para todas as séries haverá nos recreios e sob a direç̧ão dos respectivos professores, exercícios gymnasticos adaptados as condições physiologicas dos alumnos. Os trabalhos manuaes para meninas consistirão em trabalhos de agulha e prendas domésticas. Os trabalhos manuaes para meninos ficam ao critério dos professores, enquanto não estiverem as escolas convenientemente $a p p a-$ relhadas.

As applicações praticas de Agronomia serão, quanto possível, feitas em jardins ou hortas annexas às escolas. (Paraná, 1914, p. 14, grifos do original)

A despeito de sabermos que tal programa não se realizou plenamente, destacamos o número de pontos ou matérias voltados para a educação do corpo, fosse em sua perspectiva utilitária de preparação para o trabalho, fosse na perspectiva da educação dos sentidos e da compensação do esforço intelectual. Praticamente um quarto do programa se voltava para a educação do corpo; isso sem considerarmos os conteúdos da escrita, da geographia (com o desenho de mapas) e da geometria. Vale lembrar, porém, que a gymnastica não fazia parte desse rol, mas era prescrita como prática obrigatória diária nas escolas. Em síntese, o corpo e sua educação deixavam de ter lugar secundário e passavam ao centro das preocupações do currículo que se construía naqueles anos de renovação da instrução pública primária. O currículo afirmava-se como lugar de racionalização, organização e modernização do ensino primário, ainda que sua realização devesse esperar uma ou duas décadas para ser plena. Nele, a educação do corpo era uma dimensão essencial. 
Mas não era um aprendizado fácil, e era preciso recorrer a modelos exitosos. Daí a necessidade de localizar esforços de renovação pedagógica. Ainda que se tratasse da educação das crianças pequenas (jardins de infância), e não propriamente da instrução das primeiras letras, vemos parte desse investimento nas orientações dadas à professora dona Maria Francisca de Correa Miranda, em outubro de 1904, para visitar e estudar, em São Paulo, a organização do "Jardim da Infância", anexo à Escola Normal da Praça:

- Verificar a alternancia do tempo de estudo e de recreio e os jogos preferidos, de acordo com as edades das creanças no sentido de attender á educação physica das mesmas.

- Estudar as condicçóes hygienicas do estabelecimento, os moveis adoptados, a cubagem das salas em relação ao numero de alumnos, a destribuição dos recreios.

- Deverá anotar os programmas, horarios divisão do curso, condicções para matricula.

- Dos objectos necessarios ás liç̧ôes de cousas, especificados minuciosamente.

- Qual o methodo de iniciar as creanças nos conhecimentos usuais?

- Quais as recompensas e os castigos?

- Os alumnos são sujeitos á sabbatinas e exames? No caso contrario como se julga de seu aproveitamento? (Paraná, 1904, p. 36)

Inúmeras são as questões que deveriam ser objeto de observação e análise por parte da professora delegada pela diretoria da instrução pública paranaense. Mas é patente a ênfase dada à educação physica - que temos chamado de educação do corpo. Espaço, mobiliário, tempos, recreios, programas, condições de higiene, jogos, métodos, exames e até mesmo castigos e recompensas. A autoridade paranaense estava interessada em formas diversas de educação dos corpos infantis, e o modelo era São Paulo, que deveria orientar como tratar as crianças pequenas em terras paranaenses. Esse registro permite estabelecer relações entre a constituição da escolarização no Paraná, nos anos finais do século XIX, conforme viemos acompanhando, e no início do século XX, e as iniciativas de outros estados na mesma direção. Vale salientar que não podemos nos esquecer de que mesmo as iniciativas paulistas já tinham seus referentes em outros países, ditos "civilizados".

As ideias de modernização da escola, do ensino, desenvolveram-se, no Brasil, desde o século XIX. Contudo, é no início do século XX que se operaram profundas transformações na forma de conceber a instrução pública para as massas (Souza, 1998; Faria Filho, 2002; Carvalho, 2003). O estado do Paraná não estava imune a esses ventos de renovação ou de invenção de um novo modelo escolar. Tal modelo teria, na educação do corpo, um de seus pontos de ancoragem. Talvez isso ajude a explicar o sucesso tardio da "lição de coisas", um dos pontos a ser obser- 
vados em São Paulo, segundo o relatório analisado. O estudo do desenvolvimento do currículo escolar de suas relações com a educação do corpo, em perspectiva histórica, pode ajudar-nos a compreender o surgimento e o desaparecimento de determinadas matérias ou disciplinas. A bygiene escolar, os trabalhos manuaes, as prendas domésticas, o canto orfeônico já estiveram presentes no currículo da escola primária brasileira. Um estudo assim também pode ajudar a compreender a permanência de outras disciplinas na escola, tais como educação física, desenho etc. A invenção dessa escola e de seus dispositivos, entre eles o currículo, obedecia à premência de um mundo que celeremente buscava modernizar-se, distinguir-se do passado arcaico e retrógrado. Ciência, progresso, nacionalidade e trabalho comporiam um quadro que justificava a profusão de discursos e práticas sobre a educação escolar do corpo, o qual deveria levar, da experiência da escolarização, a herança de um mundo civilizado em franco e irrefreável desenvolvimento, orientado pelo saber científico.

A construção social de diferentes disciplinas escolares para a instrução pública primária no fim do século XIX obedecia à lógica das finalidades esperadas de uma escolarização em processo de mudança, ainda que essas finalidades fossem definidas a partir de um lugar específico de fala, qual seja, o lugar da civilização dos costumes. Lembremos que, para Chervel (1990), juntamente com o conteúdo e os resultados da escolarização, as finalidades declaradas ou não da escolarização são pauta obrigatória na história das disciplinas escolares.

Por sua vez, Goodson assevera que

[...] se se dá prioridade a uma compreensão do currículo e à sua mudança, então adquire importância fundamental um método de estudo que se centre nos temas "internos" e os analise. A natureza crucial dos fatores internos deriva em parte da forma como a educação e o ensino se acham estruturados e se relacionam com a economia e a sociedade. (1995, p. 23)

Assim, ao pensarmos as relações entre mudança social, cultural e mudança curricular, não podemos deixar de considerar essas relações, que se caracterizam por uma tensão permanente. A tradição seletiva que ajudaria a definir o currículo também como tradição inventada deve ser analisada pelo historiador em sua perspectiva tanto diacrônica como sincrônica, uma vez que só desse modo será possível compreender a construção social do currículo como necessidade de organização de demandas socioculturais diversas, ora marcadas pela inovação, ora marcadas pela tradição.

Por isso, interessa-nos, aqui, estabelecer nexos com reflexões que pretendiam reformar a escola - e os corpos - no âmbito nacional. Portanto, remetemos o leitor às discussões da I Conferência Nacional de Educação, promovida em 1927 pela Associação Brasileira de Educação. Em suas teses, consideramos 
poder vislumbrar algo daquilo que destaca Goodson, quando nos insta indagar o currículo em toda a sua complexidade, inclusive em suas finalidades políticas.

\section{A PARTIR DE CURITIBA: FAZER CIRCULAR PROJETOS PARA UMA EDUCAÇÃO DO CORPO NO BRASIL}

$\mathrm{Na}$ I Conferência Nacional de Educação, foram apresentadas 113 teses por meio das quais os educadores anunciaram fundamentos e propostas para uma educação moderna e para a construção de uma unidade nacional pela educação. Civismo, higiene, formação moral, aperfeiçoamento técnico, vigor físico e inovações pedagógicas foram alguns dos signos que circularam entre os educadores de diferentes regiões do país presentes durante os oito dias do evento. ${ }^{4}$

Apresentando a tese de número 5, intitulada "Necessidades da pedagogia moderna”, o professor Lindolpho Xavier, do Instituto Lafayette, da Escola Normal de Artes e Ofícios Wenceslau Braz e membro da Sociedade de Geografia do Rio de Janeiro, pretendia fazer uma espécie de diagnóstico da civilização que permitisse a valorização da educação. Iniciou assim a sua exposição:

Hoje é bem diverso: a civilização trouxe paralelamente bens e males; ensinou a imprensa, e esta espalhou complexivamente a literatura edificante e a corrosiva. Criou os altos-fornos e difundiu a máquina de tecer e a de matar; armou estaleiros onde se constroem transatlânticos e preadnoughts; fez a anilina e o gás asfixiante; apareceram o álcool, o tabaco, a cocaína, a morfina, a carta de jogar, oficializam-se as loterias.

Para cada bem uma espécie de males. É assim o mundo de hoje.

Velocidade, utilidade, especialidade.

Como complemento: materialismo, egoísmo, pragmatismo.

Missão da pedagogia: desenvolver a fraternidade e o altruísmo.

Fazer o homem sinérgico, mais simpático, mais enérgico, mais sábio, mais simples, mais prático, mais previdente, mais fraternal, mais republicano, mais religioso.

Como conseguir: ensinando-lhe a herança do passado, para que ele a use e a transmita melhor aos seus sucessores. (Costa; Shena; Schmidt, 1997, p. 65-66)

Em suas constatações sobre progresso e regressão, Lindolpho Xavier anunciava os caminhos de sua aposta na educação, continuando assim sua argumentação:

4 Sobre a I CNE, realizada em Curitiba, de 19 a 27 do dezembro de 1927, veja, entre outros trabalhos: Carvalho (1998), Vieira (2004) e Oliveira (2005). Algumas teses apresentadas no evento são aqui citadas a partir dos Anais da I CNE, estabelecidos pelo INEP, sob a organização de Costa, Shena e Schmidt (1997). 
Poderá a Pedagogia passar indiferente sobre esse perigo social?

O caráter das gerações futuras dependerá da saúde física e moral que se lhes der e de preparação e meios de defesa com que se armar.

A Pedagogia moderna tem que defender a saúde e a vida, combatendo os tóxicos, ensinando a ginástica, a higiene; tem que pregar os princípios do método e da sobriedade, aparelhando o Indivíduo para a vida ambiente.

A verdadeira Pedagogia ensinará os meios práticos de vencer na vida: pela preparação técnica, pela educação da vontade, pelo saneamento do corpo e do espírito, pelo estudo do meio físico e moral.

Toda verdadeira pedagogia tenderá para o ensino da Economia, no tempo e no espaço. Tudo no melhor processo, com um mínimo de dispêndio e o máximo de proveito, na maior velocidade. (idem, p. 71)

A preparação corporal para o trabalho não está ausente de sua pena.

Toda pedagogia moderna será fordiana: irá buscar nos livros de Ford os processos da vitória, com o máximo de humanidade, no mais intenso sistema de economia, com as generalidades das especializações. Para o fordismo não há aleijados, não há inúteis; todos cooperam para a obra geral. [...]

O progresso mecânico traz consigo grandes imposições aos homens do tempo atual. A civilização da máquina exige a mecanização do homem, qualquer que ele seja. Assim todo cidadão saberá manejar um veículo de transporte, não se considerando como educado o que não preencher esse desideratum.

Para adiantar o advento dessa era, exigir-se-á nos programas pedagógicos a ampliação das lições de mecânica e de eletricidade. (idem, p. 71-72)

Sua tônica recaía sobre o que considerava educação integral.

[...] a Associação mantém a repulsa aos estudos parcelados e recomenda a seriação em todos os estudos científicos, artísticos e literários, banindo-se o parcelamento como desorganizador da verdadeira preparação educacional.

Em todos os estudos, desde o infantil até o superior, se orientará o ensino para o lado econômico: incutindo ideias de trabalho, amor à riqueza da terra e aos hábitos de indústria e comércio.

Sempre teremos em vista que os problemas contemporâneos são e serão cada vez mais econômicos. (idem, p. 72)

Essa "educação integral" - orientada cada vez mais por uma lógica economicista, pela necessidade de mecanização do homem e pelos processos fordistas de adaptação e aperfeiçoamento - marca os corpos e os gestos com signos, tais como: saneamento corporal, velocidade, mínimo de dispêndio e máximo de proveito. Uma 
disciplina corporal nova, ampliada e racionalmente calculada, capaz de delimitar para fora e para longe de sua realização as experiências e sensibilidades corporais consideradas impróprias do ponto de vista econômico e social.

Mas as representações relativas aos conteúdos de uma educação corporal não eram uníssonas. Algumas práticas apareciam como luzes e também como sombras, na medida em que sua prescrição como conteúdo educacional, passível de escolarização, não constituía possibilidade cultural dissociada da experiência cultural já consolidada. Esse dilema, relativo ao propósito de escolarizar ou não uma prática cultural já vulgarizada - como o esporte -, ganhou expressão em outra tese, também apresentada na I CNE. A professora Raquel Prado, do Rio de Janeiro, em trabalho intitulado "A educação do futuro", deu seu comentário esportivo:

Os jogos bárbaros, como o futebol e outros, deverão ser abolidos.

Os exercícios de natação, equitação e, sobretudo, ginástica harmônica, helênica e rítmica, formarão a bela mocidade de amanhã que personalizará o tipo do genuíno brasileiro: varonil e elegante. Como a raça grega, culminará pela correção de linhas e esbeltez. A raça futura sentirá essa influência na modelagem do seu físico. Todas as escolas deverão praticar esse gênero de ginástica ao ritmo da música e, sobretudo, ao ar livre. [...]

A criança deve ser educada sob aspectos físico, emocional e mental. A cultura física, em vez de fazer o Hércules, que é um monstro com seus músculos de aço, fará do jovem um Adônis, que é a perfeição plástica na elegância de atitudes. $\mathrm{O}$ aspecto emocional no desenvolvimento dos sentidos fá-lo-á perceber as manifestações do belo, do útil e do bom! Sob o aspecto mental, desenvolverá o raciocínio rápido e terá o exato discernimento das coisas.

A finalidade filosófica da escola é criar um tipo ideal de homem para a família, a Pátria e a humanidade. (idem, p. 106)

Essa tese permite pontuar que, no âmbito da $\mathrm{ABE}$, havia uma disputa relativa ao melhor caminho a ser adotado na educação do corpo para a regeneração social e a reforma de costumes, como bem mostra Linhales (2009). Como anunciado pelo dr. Jorge de Morais, na Câmara dos Deputados, no âmbito do debate sobre educação física, existia também na $\mathrm{ABE}$ uma tensão entre defensores de uma "mentalidade esportiva" e aqueles que advogavam a "mentalidade médico-pedagógica”. Transpondo essa tensão para os modelos de regeneração, Hércules e Adônis aparecem como arquétipos em confronto e, nessa polarização, o Adônis da professora Raquel Prado guarda estreita identidade helênica com o Antinoüs, comentado por Fernando de Azevedo (1960) - um dos primeiros intelectuais brasileiros a tomar a educação física como objeto sociológico. Hércules, por sua vez, parece representar os vícios e equívocos esportivos denunciados por Carlos 
Sussekind de Mendonça, quando produziu argumentos originais para sustentar que "o sport esta[va] deseducando a mocidade brasileira" (Linhales, 2009).

A sra. Amélia de Rezende Martins, também do Rio de Janeiro, apresentou uma tese intitulada "Uma palavra de atualidade", na qual apresentou outros "problemas" relativos à educação do corpo, a partir de um foco específico: sua filiação ao grupo de educadores católicos que, no âmbito da ABE, disputavam a autoria do projeto educacional da entidade com o grupo que defendia, de forma contundente, a laicização do ensino. Seu comentário foi prioritariamente de ordem moral:

Um ponto hoje muito atacado, em se tratando da educação, é o da cultura física. Neste momento, merecem, entre nós, especial atenção os esportes. Ginástica, dança e outros começam na idade escolar e continuam em voga, com a maior aceitação na sociedade; e os esportes vão exigindo cada vez menos roupa, para que não sejam tolhidos os movimentos, e a moral leiga não acha mal em que se banhem juntos todos os meninos de todas as idades, nus, porque assim, sendo uma coisa natural e a curiosidade não ficando aguçada, a criança não vê malícia - moral leiga, moral de princípios pervertedores, sob a capa de muita ingenuidade. A criança começa não achando mau $[$ sic $]$ na nudez e acaba não achando mal em tudo que exige a nua natureza. [...] Para os esportes femininos, por tal forma a mulher se habitua a vestir pouco que depois, na sociedade, já não tem o pudor do seu corpo. Se não há mal na nudez, porque fazem os governos, os próprios governos sem crença, vestir os índios? (Costa; Shena; Schmidt, 1997, p. 155)

Como outras novidades liberais dos "sem crença", algumas práticas corporais foram ponto de questionamento para o grupo católico da $\mathrm{ABE}$, especialmente nos aspectos vinculados à moralidade, ou ao "pudor do corpo". Entretanto, a religiosidade foi ponto de aglutinação e composição com outros projetos cristãos, como aqueles realizados pelos Escoteiros Católicos e pela Associação Cristã de Moços. Essas e outras negociações disciplinares revelam permanentes negociações de sentidos no processo histórico de produção/reprodução cultural. Arranjos plurais vão ordenando um todo não necessariamente coerente, no qual as ambiguidades e os paradoxos em circulação são também elementos presentes nos costumes e nas experiências. $\mathrm{O}$ modo como a escola educa o corpo parece conectado a essa diversidade de projetos culturais em disputa.

Reflexões e propostas relativas aos procedimentos a serem adotados para a inserção de um conteúdo e/ou prática escolar na instituição de ensino permitem considerar que os saberes incorporados à escola não são sempre derivados de saberes eruditos e/ou científicos (Linhales, 2006; Taborda de Oliveira, 2006). Algumas práticas sociais tendem a se apresentar como referências nos processos de construção dos saberes escolares, especialmente pelas mediações culturais que porventura 
realizem entre a escola e outros lugares de sociabilidade e de aprendizagem. Essa trama entre o escolar e o extraescolar é tecida no jogo das seleções de conteúdos que, por sua vez, parecem sempre associadas ao exercício de tornar escolar o que antes não o era. Vemos aí uma modelagem de tempos e espaços, de sujeitos e objetos, logo, de corpos.

Outro fragmento dessa trama pôde ser encontrado na tese número 42, sobre "A uniformização do ensino primário", apresentada por Lourenço Filho. Seus argumentos, que, segundo ele, tinham motivações mais sociológicas que didáticas, estavam relacionados à defesa que fazia de uma organização e de uma unidade nacional para o ensino primário. Mesmo reconhecendo as especificidades regionais, Lourenço Filho anunciou o que considerava "os aprendizados fundamentais", práticas e disciplinas escolares por ele consideradas necessárias à "formação humana". Ele fez considerações sobre a leitura, a escrita, o cálculo, a geografia, a história, as ciências naturais, o desenho etc. e acrescentou "a tudo isso a iniciação à cultura física e o gosto pelo desporto. Mesmos os menos preparados dos mestres podem ser arvorados em chefes de jogos educativos, como futebol ou bola-ao-cesto e outros exercícios" (Costa; Shena; Schmidt, 1997, p. 249). Destaque-se que suas premissas já eram objeto de seu ensino no âmbito das Escolas Normais (Taborda de Oliveira, 2009). Naquele âmbito, por exemplo, Lourenço Filho produziu um conjunto de aulas ou lições ministradas na Escola Normal do Ceará, em 1923 (Bastos; Cavalcante, 2009). Se considerarmos que o estado do Ceará se encontrava geograficamente longe dos principais centros do país, e mesmo de Curitiba, podemos então dimensionar a força da circulação das ideias mobilizadas no Brasil naquele período.

A partir dessas diferentes teses que circularam na I CNE, parece plausível indiciar que, na produção de uma (re)forma escolar para a modernização e a regeneração social, a temática da educação do corpo aparecia com bastante conforto e sintonia. Ferdinando Labouriau, membro da diretoria da ABE no período, apresentou tese defendendo a criação de um Ministério de Educação Nacional, como estratégia capaz de superar a "dispersão de esforços", a "falta de coordenação" e a "ausência de diretivas". Com essas expressões, defendia a unidade nacional e o que chamava de visão do problema em conjunto. Conforme Labouriau:

Assim como o problema da siderurgia não interessa apenas aos estados onde há minério de ferro, assim como a questão do café não interessa somente aos estados produtores da rubiácia, sendo ambos, realmente, problemas nacionais, assim também o problema da educação não é meramente uma questão pedagógica, e sim um problema nacional. É mesmo o maior dos problemas nacionais. (Costa; Shena; Schmidt, 1997, p. 269)

Esse trabalho fora publicado um mês antes na revista $A$ Bandeira, do Club dos Bandeirantes do Brasil. A ABE, conectada ao clima cultural, fazia circular essas novas referências, novas interações, novas linguagens. Muitos educadores presentes 
na I CNE defendiam que as salas de aula deveriam ser "mais vivas", os alunos "mais ativos" em seus processos de aprendizagem, a educação escolar "mais eficiente" diante dos problemas nacionais. Nesse exercício de consolidação de uma "Escola Nova", outros espaços foram, gradativamente, a partir da escola, legitimados como lugares educativos complementares: museus, cinemas, bibliotecas, estádios e quadras esportivas, todos capazes de estimular os sentidos e produzir novas sensibilidades. Como todo movimento político e cultural, também esse movimento comportava uma diversidade de mensagens em correlação. Como um amálgama de projeções e práticas, passou a circular e a estabelecer-se como a nova pedagogia, estendendo, pela trama da cidade, o propósito de "construir um estado de espírito moderno", eminentemente corpóreo e sensível (Nunes, 2000, p. 374).

\section{EM BUSCA DE NOVAS PISTAS}

Ao articular estudos curriculares com a história da escolarização, tendo como premissa uma possível história do corpo e sua importância para a formação humana, procuramos compreender permanências e rupturas que marcaram a relação entre escolarização e educação do corpo. Os pequenos exemplos destacados, extraídos de documentação variada, em tempos e lugares diversos, indicam que o processo de reforma da escola, com a consequente inovação curricular, atenderia a demanda de um mundo que mudava rapidamente. Isso mesmo que no contexto de uma sociedade de lento desenvolvimento, como era particularmente o caso do estado do Paraná, nos anos aqui estudados, mas que de alguma maneira representa um pouco do que eram os projetos para o Brasil de então. Com os elementos oferecidos pelo tempo e pelas circunstâncias em que viveram, agentes escolares - professores, inspetores, alunos, pais - ajudaram a semear as bases do que seria a implantação de disciplinas diversas na instrução pública primária, consoantes com os discursos que enalteciam a necessária reformulação das práticas escolares. Um número significativo daquelas disciplinas tinha a educação do corpo como centro de suas preocupações e seria objeto de preocupação de intelectuais e de projetos de organização social e cultural dos mais diversos matizes, como pudemos observar na documentação referente à Conferência de 1927, com alcance nacional.

Quanto à escola primária do fim do século XIX e do início do século XX, ela parece ter compreendido o papel da educação do corpo para a formação (Souza, 2005). Ao compreender aquele papel a partir várias de demandas, a escola ajudou a definir e a consolidar saberes, práticas e disciplinas; algumas teriam vida longa nos currículos escolares, a exemplo da educação física, entre outras. Assim, o desafio posto é justamente compreender historicamente as interseções entre a cultura, a escola e a educação do corpo por meio do estudo histórico do currículo e das disciplinas escolares que, por ventura, sintetizaram aquela relação. Essa mirada pode ainda articular, em um país tão plural como o Brasil, marcas do que poderia ser 
tomado como nacional ou local, que configuram uma dispersão passível de alguma unidade nos discursos renovadores.

Mapeando e catalogando fontes, identificando novos acervos, ampliando o diálogo com a literatura e, sobretudo, ampliando a compreensão histórica da educação do corpo na escola para além dos limites de seu conteúdo sem, contudo, excluí-lo, podemos contribuir de forma bastante significativa para a compreensão do lento processo de afirmação da forma escolar como modo privilegiado de socialização, uma vez que podemos entender os vários dispositivos mobilizados para controle dos corpos por diferentes formas escolares em diferentes períodos da história da escolarização e em diferentes regiões do Brasil. Essa perspectiva deve abrir e/ou ampliar os canais de diálogo entre as diferentes áreas do saber que atravessam a compreensão dos processos de formação: a pedagogia, a psicologia, a filosofia, a antropologia, a psicanálise, a sociologia, a medicina, a linguística, a biologia, entre outras, todas elas focadas a partir das lentes dos historiadores da educação. A instituição dos mais diversos saberes escolares e de práticas calcadas sobretudo no imperativo da educação corporal confere ao historiador da educação um campo fecundo de possibilidades pouco exploradas: o nascimento, a mudança e o desaparecimento de diversas disciplinas escolares; a instituição de práticas e rituais que enalteciam a formação do espírito através do investimento sobre o corpo, como as festas, o escotismo, os desfiles os batalhões escolares; a transformação de padrões de entendimento e de comportamento corporal no âmbito de diferentes culturas escolares (questões afeitas à sexualidade, à definição dos papéis sexuais, ao utilitarismo corporal, à violência material e simbólica à qual os corpos são submetidos etc.); a padronização de condutas manifesta em uma definição cada vez mais precisa dos tempos e espaços de aprender e dos tempos e espaços de brincar, como a duração das aulas, os tempos de recreio, as atividades permitidas e as proibidas naqueles tempos. Um conjunto nada desprezível de manifestações relacionadas à corporalidade que ajudou a configurar o que conhecemos como o processo de escolarização e, mais precisamente, a construção do currículo da escola primária, que, mais que instruir, pretendeu e pretende formar. João Gualberto Franco de Bittencourt, em documento intitulado "Educação, o que difere da instrução e quais seus ramos?”, já indicava isso ao afirmar que das três faculdades, "physicas", "moraes" e "intellectuaes", "é de se destacar a physica como de maior valor" (1879).

Contribuir para compreender historicamente como essa dimensão physica ou corporal ajudou a conformar o currículo da escola primária brasileira e diferentes disciplinas escolares, no mesmo movimento que por elas foi transformada, foi o objetivo primeiro deste trabalho. Isso nos instiga ainda a compreender melhor o processo histórico de mobilização dos corpos infantis (pela forma escolar de socialização) na consolidação do imaginário da modernidade, geradora por excelência, segundo Walter Benjamin (1994), desse "frágil e minúsculo corpo humano", tão importante para o projeto de consolidação da escolarização. 


\section{REFERÊNCIAS}

Associação Brasileira de Educação. Anais da I Conferência Nacional de Educação. Curitiba, 1927.

Azevedo, Fernando de. Da educação física: o que ela é, o que tem sido e o que deveria ser. In: Obras completas. 3. ed. São Paulo: Melhoramentos, 1960, v. I.

Bastos, Maria Helena Camara; Cavalcante, Maria Juraci Maia. O curso de Lourenço Filho na Escola Normal do Ceará. Campinas: Alínea, 2009.

Benjamin, Walter. Magia e técnica, arte e política: ensaios sobre literatura e cultura. In: Obras escolbidas. 7. ed. São Paulo: Brasiliense, 1994, v. 1.

Bittencourt, João Gualberto Franco de. Educação, o que difere da instrução e quais seus ramos?. Relatório enviado ao presidente da província do Paraná. Departamento Estadual de Arquivo Público, 1879.

Carvalho, Marta Maria Chagas de. Quando a história da educação é a história da disciplina e da higienização das pessoas. In: Freitas, Marcos Cezar (Org.). História social da infância no Brasil. São Paulo: Cortez, 1997.

. Molde nacional e forma civica: higiene moral e trabalho no projeto da Associação Brasileira de Educação (1924-1931). Bragança Paulista: EDUSF, 1998.

. A escola e a república e outros ensaios. Bragança Paulista: EDUSF, 2003.

Chervel, André. História das disciplinas escolares: reflexões sobre um campo de pesquisa. Teoria e Educação, n. 2, p. 177-229, 1990.

Costa, Maria José; ShenA, Denílson; Schmidt, Maria Auxiliadora (Org.). I Conferência Nacional de Educação. Brasília: INEP, 1997.

FARIA FiLHo, Luciano Mendes de. Instrução elementar no século XIX. In: LOPEs, Eliane Marta Teixeira; Faria Filho, Luciano Mendes de; Veiga, Cynthia Greive (Org.). 500 anos de educação no Brasil. Belo Horizonte: Autêntica, 2000a.

Escolarização, culturas e práticas escolares no Brasil: elementos teórico-metodológicos de um programa de pesquisa. In: LoPEs, Alice; MACEDO, Elizabeth. Disciplinas e integração curricular: histórias e políticas. Rio de Janeiro: DP\&A, $2000 \mathrm{~b}$.

. Escolarização e cultura escolar no Brasil: reflexões em torno de alguns pressupostos e desafios. In: BencostTA, Marcus Levy Albino. Culturas escolares, saberes e práticas educacionais: itinerários históricos. São Paulo: Cortez, 2007.

FrankLIN, Barry. La historia del curriculum en Estados Unidos: status y agenda de investigación. Revista de Educación, v. 1, n. 295, maio/ago., 1991.

Ginzburg, Carlo. O queijo e os vermes. São Paulo: Companhia das Letras, 1985.

Goodson, Ivor. Historia del curriculum. Barcelona: Pomares-Corredor, 1995.

Julia, Dominique. A cultura escolar como objeto histórico. Revista Brasileira de História da Educaşão, n. 1, p. 9-44, 2001. 
Disciplinas escolares: objetivos, ensino e apropriação. In: LoPEs, Alice; MACEDO, Elizabeth (Org.). Disciplina e integração curricular: história e políticas. Rio de Janeiro: DP\&A, 2002.

Linhales, Meily Assbú. A produção de uma forma escolar para o esporte: os projetos culturais da Associação Brasileira de Educação (1926-1935) como indícios para a historiografia da Educação Física. In: TABorda de OliveIRA, Marcus Aurélio. Educação do corpo na escola brasileira. Campinas: Autores Associados, 2006.

. A escola e o esporte: uma história de práticas culturais. São Paulo: Cortez, 2009.

Nunes, Clarice. (Des)encantos da modernidade pedagógica. In: LoPEs, Eliane Marta Teixeira; Faria Filho, Luciano Mendes de; VeIga, Cynthia Greive (Org.). 500 anos de educação no Brasil. Belo Horizonte: Autêntica, 2000.

Oliveira, Marília Cruz. Recreação, divertimentos infantis e educação nas teses da I Conferência Nacional de Educação (1927). 2005. Monografia (Especialização em Lazer) UFMG, Minas Gerais, 2005.

Paraná. Departamento de Arquivo Público do Paraná, Coleção Correspondência do Governo, v. 16, p. 1.203, 1904.

. Relatório do diretor-geral da Instrução Pública, Francisco de Azevedo Macedo, ao presidente da Provincia do Paraná, 1914.

Pineau, Pablo. Premisas básicas de la escolarización como construcción moderna que construyó a la modernidad. Revista de Estudios del Curriculum, v. 2, n. 1, 1999.

SAcristán, José Gimeno. O currículo: uma reflexão sobre a prática. Porto Alegre: Artmed, 2000.

SoAres, Carmen Lúcia. Imagens da educação no corpo. Campinas: Autores Associados, 1998.

. Notas sobre a educação do corpo. Educar em Revista, n. 16, p. 43-60, 2000.

SouzA, Rosa Fátima de. Templos de civilização. São Paulo: UNESP, 1998.

. Cultura escolar e currículo: aproximações e inflexões nas pesquisas históricas sobre conhecimentos e práticas escolares. In:XAVIER, Libânia Nacif et al. (Org.). Escola, culturas e saberes. Rio de Janeiro: FGV, 2005.

Taborda de Oliveira, Marcus Aurelio. Educação do corpo na escola brasileira. Campinas: Autores Associados, 2006.

. Atividade e natureza: a educação física para o ensino primário. In: BASTOS, Maria Helena; Cavalcante, Maria Juraci (Org.). O curso de Lourenço Filho na Escola Normal do Ceará. Campinas: Alínea, 2009.

Thompson, Edward. Costumes em comum. São Paulo: Companhia das Letras, 1998.

VAGO, Tarcísio Mauro. Cultura escolar, cultivo de corpos: educação physica e gymnastica como práticas constitutivas dos corpos de crianças no ensino público primário de Belo Horizonte (1906-1920). Bragança Paulista: EDUSF, 2002. 
VIDAL, Diana Gonçalves. Múltiplas estratégias de escolarização da infância. Anais do III Congresso Brasileiro de História da Educação. Curitiba: SBHE, 2004.

. Culturas escolares: estudos sobre práticas de leitura e escrita na escola pública primária (Brasil e França, final do século XIX). Campinas: Autores Associados, 2005. VIEIRA, Carlos Eduardo. O discurso da modernidade na I Conferência Nacional de Educação (Curitiba - 1927). In: Congresso Brasileiro de História Da Educação, 3., 2004, Curitiba: PUC, 2004.

VIncent, Guy (Org.). L'education prisonnère de la forme scolaire? Scolarisation et socialisation dans les sociétés industrielles. Lyon: Presses Universitaires de Lyon, 1994.

; LAHIRE, Bernard; Thin, Daniel. Sobre a história e a teoria de forma escolar. Educação em Revista, n. 33, 2001.

\section{SOBRE OS AUTORES}

Marcus Aurelio Taborda de Oliveira é doutor em história e filosofia da educação, com pós-doutorado em historia de la educación pela Universidad de Murcia, Espanha. Professor do Departamento de Teoria e Prática de Ensino e do Programa de Pós-Graduação em Educação, linha de pesquisa História e Historiografia da Educação, da Universidade Federal do Paraná. E-mail: marcustaborda@uol.com.br

Meily Assbú Linhales é doutora em educação pela Universidade Federal de Minas Gerais. Professora do Departamento de Educação Física e do Programa de Pós-Graduação em Educação e Inclusão Social da mesma instituição. E-mail:meily_linhales@yahoo.com.br 


\section{MARCUS AURELIO TABORDA DE OLIVEIRA E MEILY ASSBÚ LINHALES}

Pensar a educação do corpo na e para a escola: indícios no debate educacional brasileiro (1882-1927)

O trabalho procura pontuar um debate sobre a educação do corpo na escola primária brasileira entre os anos finais do século XIX e iniciais do XX, 
articulando uma dimensão local - a província do Paraná - com outra nacional - a I Conferência Nacional de Educação, de 1927. Percorrendo fontes de naturezas diversas, localiza em diferentes registros a ênfase sobre uma necessária educação do corpo dos escolares como uma das principais vias de modernização e civilização da sociedade. Inscrito na perspectiva de uma história do currículo, o trabalho pretende problematizar a hipótese de que a dimensão física ajudou a conformar o currículo da escola primária brasileira, ainda a ser refinada, mais do que afirmar como definitivo os pressupostos aqui explorados.

Palavras-chave: história da escola; história do currículo; história das disciplinas escolares; educação do corpo; educação dos sentidos

\section{Thinking the education of body in and for the school: evidences within the Brazilian educational debate (1882-1927)}

This work intends to situate a Brazilian debate concerning body education in the primary school in the period between the late $19^{\text {th }}$ century and early $20^{\text {th }}$ century. To this purpose, we analyzed, jointly, a local educational context - in the Province of Parana - and a national event on education - the $1^{\text {st }}$ National Conference of Education, happened in 1927. Going through a variety of sources, we found a frequent emphasis on the need of body education for the schoolchildren as the main way to reach a modern and civilized society. Engaged with the approach from the history of curriculum, this work aims to debate and, thus, to refine one bypothesis, more than assert as definite the presuppositions here explored.

Keywords: history of school; history of curriculum; history of school disciplines; body education; education of senses

\section{Pensar la educación del cuerpo en la escuela y para la escuela: indicios en el debate educativo brasileño (1882-1927)}

El trabajo busca analizar un debate sobre la educación del cuerpo en la escuela primaria brasileña desde los años finales del siglo XIX hacia los años iniciales del siglo XX. Articula una dimensión local de la Provincia de Paraná con la dimensión nacional de la I Conferencia Nacional de Educación, en 1927. Mirando fuentes de naturaleza diversa, analiza en distintos registros el énfasis en la necesidad de educación de los cuerpos de los escolares como una de las principales vías de modernización y civilización de la sociedad. Desde la perspectiva de la historia del curriculum, el trabajo intenta problematizar una hipótesis aun provisoria más que afirmar como definitivas las ideas aqui exploradas.

Palabras clave: historia de la escuela; historia del curriculum; historia de las disciplinas escolares; educación del cuerpo; educación de los sentidos 